\title{
Dopaminergic regulation of gonadotrophin secretion in seasonally anoestrous mares
}

\author{
B. Besognet, B. S. Hansen and P. F. Daels* \\ Department of Clinical Sciences, College of Veterinary Medicine, Cornell University, Ithaca, NY 14853 , \\ USA
}

We have previously demonstrated that daily administration of the dopamine D2 antagonist, sulpiride, during seasonal anoestrus, effectively advances the mean time of onset of the breeding season in mares. The purpose of this study was to examine the effect of sulpiride administration on pulsatile FSH and LH secretion in seasonally anoestrous mares, follicular development, time of first ovulation and the fertility at the first ovulation. Fourteen anoestrous mares were selected based on progesterone concentrations $<1 \mathrm{ng} \mathrm{ml}{ }^{-1}$ for 3 weeks and largest follicle diameter $<20 \mathrm{~mm}$. Starting 30 January, eight seasonally anoestrous mares were treated daily with sulpiride until the first ovulation of the year, and six untreated control mares were maintained under the same environmental conditions. Ovarian activity was monitored and plasma samples were collected every other day. On days 1,11 and 21 of treatment, plasma samples were collected every $15 \mathrm{~min}$ for $11 \mathrm{~h}$ in six treated and six control mares. Mares were bred during the first oestrus. Mean time of first ovulation was significantly advanced in sulpiride-treated mares compared with control mares. Pregnancy rate 18 days after ovulation was similar between groups. Mean FSH pulse frequency on the first day of treatment and mean plasma FSH concentrations on day II of treatment were significantly higher in sulpiride-treated mares compared with control mares. No significant difference was observed between groups for parameters of $\mathrm{LH}$ pulsatile secretion. The results of this study suggest that dopamine inhibits FSH pulsatile secretion in seasonally anoestrous mares.

\section{Introduction}

The role of dopamine in the regulation of reproductive function has been examined in several vertebrate species (Meyer and Goodman, 1985, 1986; Seki et al., 1986; Van Asselt et al., 1988; Thompson et al., 1992; Sotowska-Brochocka et al., 1994). In general, dopamine appears to play a major role in the regulation of seasonal reproductive activity and puberty. In ewes, dopamine exerts an inhibitory effect on LH secretion during seasonal anoestrus, mediating the oestradiol negative feedback on the hypothalamo-hypophyseal axis (Havern et al., 1994). In ovary-intact ewes and ovariectomized-oestradioltreated ewes, systemic administration of a dopamine D2 antagonist significantly increases LH pulse frequency, resulting in increased mean $\mathrm{LH}$ serum concentrations, during anoestrus but not during the physiological breeding season (Meyer and Goodman, 1985, 1986; Kao et al., 1992; Le Corre and Chemineau, 1993).

In mares, FSH and LH pulses, detected in jugular blood, have been reported in anoestrous, intact mares. During seasonal anoestrus, the frequency of pulses ranges from zero to two per $12 \mathrm{~h}$ and most FSH and LH pulses are coincident. An increase

\section{*Correspondence.}

Revised manuscript received 16 April 1996. in pulse frequency combined with a decrease in pulse amplitude for both LH and FSH has been observed during the transition to cyclic ovarian activity (Fitzgerald et al,, 1987; Thompson et al., 1987; Alexander and Irvine, 1991; Hines et al., 1991). Dopamine also exerts a tonic inhibition on reproductive activity during seasonal anoestrus (Besognet et al., 1995a). Daily administration of a dopamine D2 antagonist, sulpiride, starting at the beginning of February, significantly advanced the day of first ovulation and the onset of the ovulatory season in seasonally anoestrous mares. During the transition from anoestrus to cyclic reproductive activity, a primary follicular wave develops and a dominant follicle emerges and ovulates (Ginther, 1992). The onset of ovarian activity is associated with an increase in LH and FSH pulse frequency (Alexander and Irvine, 1991). However, the mechanisms regulating gonadotrophin secretion during vernal transition remain unclear (Sharp et al., 1991).

The purpose of the present study was to examine the effect of treatment with the dopamine D2 antagonist, sulpiride, on FSH pulsatile secretion during seasonal anoestrus in mares. Frequent jugular blood samples (every $15 \mathrm{~min}$ ) were used to determine the pulsatile pattern of FSH and LH secretion during the transitional period and to compare gonadotrophin secretion patterns in sulpiride-treated with those in untreated anoestrous mares. In addition, the effects on follicular development, time of 
first ovulation and fertility of the first ovulation after sulpiride treatment were examined.

\section{Materials and Methods}

Animals

Fourteen horse mares from varying breeds, weighing $480-650 \mathrm{~kg}$ and aged $4-17$ years, were used in this study. At the beginning of the study, all mares had had a normal reproductive history for at least $I$ year, were not pregnant, not lactating and had been kept at the same location (Cornell University Equine Research Park, Ithaca, NY, latitude $42^{\circ} 27^{\prime}$ north) on pastures, for at least 1 year. All mares were maintained under natural photoperiod, in a large paddock with free access to a shed. Mares were fed a balanced diet of hay, grains and minerals and had free access to water. At the beginning of the experiment, all mares were confirmed to be in seasonal anoestrus based on ovarian quiescence (follicle diameter $<20 \mathrm{~mm}$ ) and plasma progesterone concentrations below $1 \mathrm{ng} \mathrm{ml}{ }^{-1}$ in three samples taken at intervals of I week during January.

\section{Treatment}

Mares were randomly divided into a treatment group $(n=8)$ and a control group $(n=6)$. Mares in the treatment group received sulpiride, suspended in sesame oil (100 $\mathrm{mg} \mathrm{ml}^{-1}$ ), daily (between 08:00 h and 09:00 h) via intramuscular injection. The dose of sulpiride $\left(( \pm)\right.$-sulpiride, $1 \mathrm{mg} \mathrm{kg}{ }^{-1}$ bodymass, Sigma Chemicai Company, St Louis, MO) was based on our previous study with anoestrous mares but was adjusted for bodymass (Besognet et al., 1995a). Treatment was started on 30 January $(n=4)$ or 31 January $(n=4)$, and was continued daily until the day of first ovulation of the year for each mare. Mares in the control group $(n=6)$ did not receive any treatment.

\section{Experimental procedure}

The experiment was performed from January to May 1995. To assess reproductive status and monitor ovulation, mares were examined by transrectal palpation and ultrasonography every other day between $08: 00 \mathrm{~h}$ and $09: 00 \mathrm{~h}$ or every day when a follicle larger than $35 \mathrm{~mm}$ was present. Blood samples were collected by jugular venipuncture in heparinized tubes (Vacutainer, Becton Dickinson, Rutherford, NJ) on the days of rectal examination, until $\mathrm{I}$ week after the second ovulation of the year. Plasma was separated immediately by centrifugation (at $1500 \mathrm{~g}$ for $10 \mathrm{~min}$ at $4^{\circ} \mathrm{C}$ ) and stored frozen at $-20^{\circ} \mathrm{C}$ until progesterone analysis.

\section{Frequent-sampling procedures}

On days 1,11 and 21 of treatment, jugular blood samples were obtained from six of the eight sulpiride-treated mares and the six control mares, via an indwelling teflon catheter (Milacath, Mila International Inc., Covington, KY), every $15 \mathrm{~min}$ for $11 \mathrm{~h}$, starting $15 \mathrm{~min}$ before sulpiride administration (at 09:00 h). Catheterization of the jugular vein was performed I $\mathrm{h}$ before the start of experimental sampling and the catheter was removed at the end of each sampling period. Blood was collected by syringe, transferred into heparinized tubes and chilled immediately. Plasma was separated and stored frozen at $-20^{\circ} \mathrm{C}$ until $\mathrm{LH}$ and $\mathrm{FSH}$ concentrations were measured.

\section{Fertility study}

Mares were bred to a fertile stallion during the first oestrus. Mares were inseminated with fresh semen ( $>500$ million progressively motile sperm cells) every other day starting the day a follicle $>40 \mathrm{~mm}$ was present until ovulation was observed or until the largest follicle was $<40 \mathrm{~mm}$. Pregnancy status was determined 18 days after ovulation by ultrasonography.

\section{Hormone analyses}

Progesterone. Progesterone concentrations were determined in ether-extracted plasma samples using an enzyme immunoassay (Munro and Stabenfeldt, 1984). The limit of sensitivity of the assay was $0.05 \mathrm{ng} \mathrm{ml}^{-1}$ plasma. The mean intra- and interassay coefficients of variation were $8.5 \%$ and $15.0 \%$, respectively.

Luteinizing hormone. Plasma LH concentrations were determined by heterologous double-antibody radioimmunoassay (Roser and Hughes, 1991). Highly purified equine LH (eLH, E263B, H. Papkoff, University of California, Davis, CA) was used for standards and iodination and the first antibody was a mouse anti-bovine LH- $\beta$ antibody (monoclonal antibody, 518B7, J. F. Roser, University of California, Davis, CA). The limit of sensitivity of the assay was $0.65 \mathrm{ng} \mathrm{ml}^{-1}$ plasma. The mean intra- and interassay coefficients of variation were $8.0 \%$ and $9.0 \%$, respectively.

Follicle-stimulating hormone. Plasma FSH concentrations were determined by heterologous double-antibody radioimmunoassay (Roser and Hughes, 1991). Highly purified equine FSH (E265B, H. Papkoff, University of California, Davis, CA) was used for standards and iodination and the first antibody was a rabbit anti-human FSH (anti-human FSH-6 antisera, AFP-005, National Hormone and Pituitary Program, Rockville, MD). The limit of sensitivity of the assay was $4.0 \mathrm{ng}$ $\mathrm{ml}^{-1}$ plasma. The mean intra- and interassay coefficients of variation were $6.8 \%$ and $8.0 \%$, respectively.

\section{Statistical analyses}

The pulsatile patterns of circulating LH and FSH in blood samples collected every $15 \mathrm{~min}$ for $11 \mathrm{~h}$ were determined using PC-Pulsar (J. Gitzen and V. Ramirez, University of Illinois, Urbana, IL). Mean and basal plasma concentrations, pulse amplitude and pulse frequency were calculated for each frequent sampling period. A pulse was defined as an increase in FSH or LH plasma concentration from a preceding nadir, exceeding the sensitivity of the assay, and was identified using standard deviation criteria (Merriam and Wachter, 1982). Basal 
Table 1. Number of LH and FSH pulses and diameter of largest follicle observed in control mares $(n=6)$ and sulpiride-treated mares $(n=6)$ on days 1,11 and 21 of treatment

\begin{tabular}{|c|c|c|c|c|c|c|c|c|c|}
\hline \multirow{2}{*}{$\begin{array}{l}\text { Day of year of } \\
\text { first ovulation }\end{array}$} & \multicolumn{3}{|c|}{ Number of LH pulses } & \multicolumn{3}{|c|}{ Number of FSH pulses } & \multicolumn{3}{|c|}{$\begin{array}{c}\text { Follicle } \\
\text { diameter }(\mathrm{mm})\end{array}$} \\
\hline & Day 1 & Day 11 & Day 21 & Day 1 & Day 11 & Day 21 & Day 1 & Day 11 & Day 21 \\
\hline \multicolumn{10}{|l|}{ Control } \\
\hline 90 & 0 & 1 & 0 & 1 & 1 & 1 & 20 & 30 & 28 \\
\hline 94 & 0 & 0 & 1 & 0 & 0 & 1 & 10 & 20 & 15 \\
\hline 95 & $1^{*}$ & 1 & 1 & 0 & 1 & 1 & 15 & 15 & 20 \\
\hline 116 & 0 & 0 & 0 & 0 & 0 & 0 & 10 & 15 & 20 \\
\hline 119 & 0 & 0 & 0 & 0 & 0 & 0 & 15 & 10 & 10 \\
\hline 123 & 0 & 0 & 0 & 0 & 0 & 0 & 10 & 12 & 15 \\
\hline Mean & & & & & & & 13.3 & 17 & 18 \\
\hline \multicolumn{10}{|l|}{ Treated } \\
\hline 53 & 0 & 0 & 0 & $I$ & 1 & 0 & 20 & 23 & 55 \\
\hline 70 & 1 & $2^{*}$ & 1 & $I$ & 1 & 1 & 20 & 27 & 37 \\
\hline 72 & 1 & $1^{*}$ & $1^{*}$ & 2 & 1 & 0 & 15 & 25 & 20 \\
\hline 94 & 0 & 1 & 0 & $I$ & 0 & 1 & 10 & 10 & 15 \\
\hline 101 & 0 & 0 & 0 & 0 & $I$ & 0 & 15 & 15 & 25 \\
\hline 129 & 0 & 0 & 1 & 0 & 0 & 1 & 15 & 30 & 27 \\
\hline Mean & & & & & & & 15.8 & 21.7 & 29.8 \\
\hline
\end{tabular}

Blood samples were taken every $15 \mathrm{~min}$ for $11 \mathrm{~h} .{ }^{*} \mathrm{LH}$ pulse not concurrent with FSH pulse.

concentrations of $\mathrm{LH}$ and FSH during the $11 \mathrm{~h}$ frequent sampling periods were derived by removal of peaks using the PC-Pulsar program. Effect of day of sampling on gonadotrophin concentrations and amplitude of pulses during frequent sampling were evaluated using analysis of variance for repeated measures. Mean gonadotrophin concentrations, amplitude of pulses and mean diameter of the largest follicle, for sulpiridetreated mares and nontreated mares, were compared within days using Student's $t$ test. Differences between groups for LH and FSH pulse frequencies were analysed using a MannWhitney test. Mean time of first ovulation and mean size of preovulatory follicle for control and sulpiride-treated mares were compared using Student's $t$ test. All values are given as mean \pm SEM. Statistical significance was considered at $P \leq 0.05$. All statistical analyses were performed using the statistical computer software Minitab (Minitab, Inc., State College, PA).

\section{Results}

\section{First ovulation}

The first ovulation in the eight sulpiride-treated mares occurred on days 53,70,72,72, 90, 94, 101 and 129, respectively (day of year). For the six nontreated mares, first ovulation occurred on days 90,94,95, 116, 119 and 123, respectively, and the duration of treatment ranged from 23 days to 98 days. Mean time of first ovulation was significantly advanced $(P<0.05)$ for sulpiride-treated mares $(85.1 \pm 8.3$ days) when compared with nontreated mares (106.2 \pm 6.0 days). The mean size of the first preovulatory follicle was not significantly different $(P>0.05)$ for sulpiride-treated mares $(49.2 \pm 1.5 \mathrm{~mm})$ when compared with control mares
$(49.8 \pm 1.0 \mathrm{~mm})$. The first inter-ovulatory intervals for the four sulpiride-treated mares that were not pregnant after the first ovulation were 19,22, 27 and 47 days, respectively. One treated mare had a long first interovulatory interval (47 days), including a normal luteal phase ( 15 days) followed by an anoestrous period. The first interovulatory intervals for the two nonpregnant control mares were 21 and 22 days, respectively.

\section{Pregnancy rate}

Four out of seven $(57 \%)$ sulpiride-treated mares bred during the first oestrus were pregnant 18 days after first ovulation which occurred on days 70,72, 101 and 129, respectively. Similarly, four of the six $(67 \%)$ control mares were pregnant 18 days after the first ovulation which occurred on days $90,94,95$ and 123 , respectively.

\section{Follicular development}

The diameters of the largest ovarian follicle present in mares used for frequent sampling on days 1,11 and 21 of treatment are presented in Table 1, and the diameters of the largest follicle for individual mares are shown (Fig. 1). Mean size of the largest follicle tended to be larger for sulpiride-treated mares on day 21 of treatment $(P=0.057$, Table 1$)$. Mares that ovulated early tended to have larger follicles compared with mares ovulating later.

\section{FSH secretion}

On days 1,11 and 21 of treatment, 0-2 FSH pulses per $11 \mathrm{~h}$ were observed in jugular blood samples taken every $15 \mathrm{~min}$ 


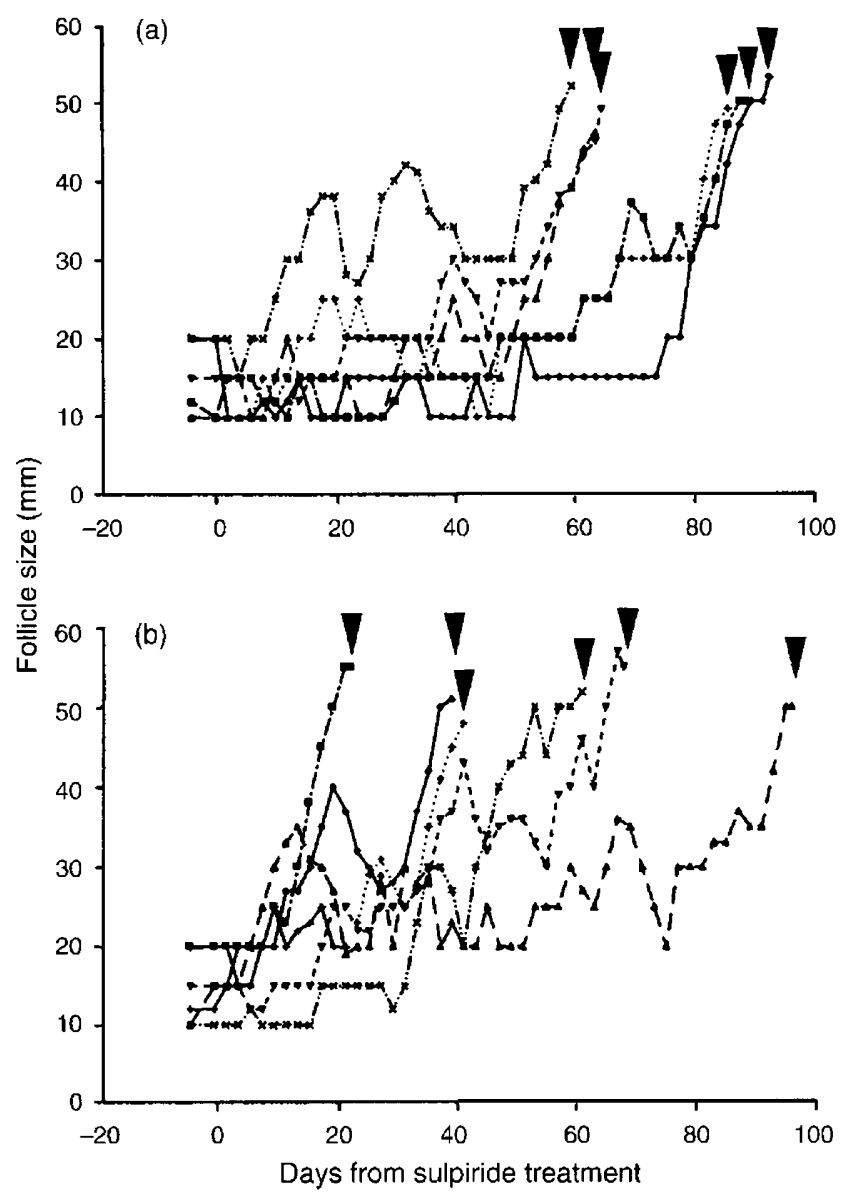

Fig. 1. Diameter of the largest follicle present on the ovaries of individual mares in (a) the control group, and (b) the sulpiride-treated group. Day of ovulation is indicated by $(\boldsymbol{\nabla})$.

(Table 1). A total of $12 \mathrm{FSH}$ pulses were observed in sulpiride-treated mares and six FSH pulses were observed in control mares. Means of parameters for FSH pulsatile secretion, recorded on days I, 11 and 21 of treatment, are presented (Fig. 2). Day of treatment had no significant effect on the pulsatile secretion parameters. On the first day of treatment, mean FSH pulse frequency was significantly higher $(P=0.05)$ in sulpiridetreated mares compared with controls, but not significantly different $(P>0.05)$ on subsequent days. Mean and basal plasma FSH concentrations were significantly higher in sulpiridetreated mares compared with nontreated mares on day 11 of treatment $(P<0.05)$ and tended to be greater on days 1 and 21 , but differences were not statistically significant $(P>0.05)$. No significant difference $(P>0.05)$ between groups was observed for FSH pulse amplitude (Fig. 2).

\section{LH secretion}

A total of $14 \mathrm{LH}$ pulses ( $0-2$ per $11 \mathrm{~h}$ ) were observed on days 1, 11 and 21 of treatment (Table 1). Nine LH pulses were detected in sulpiride-treated mares and five pulses in control mares. Mean parameters for $\mathrm{LH}$ pulsatile secretion, recorded on days 1, 11 and 21 of treatment, are represented (Fig. 3). As for FSH, the day of treatment had no significant effect on LH pulsatile secretion parameters. Means of parameters measured for LH pulsatile secretion did not differ significantly $(P>0.05)$ between sulpiride-treated mares and nontreated mares but values tended to be greater on each treatment day. Ten out of $14 \mathrm{LH}$ pulses $(71 \%)$ were coincident with FSH pulses. High basal plasma LH concentrations ( $7-27 \mathrm{ng} \mathrm{ml}^{-1}$ ) were observed on the 3 days of sampling in two treated and two control mares (ovulation occurred on days 70 and 72 for the treated and days 94 and 95 for the control mares).

\section{Discussion}

The present study adds further support to our hypothesis that dopamine plays a role in the regulation of seasonal reproduction in anoestrous mares (Besognet et al., 1995a). As in our previous study, follicular development was advanced and mean time of first ovulation occurred significantly earlier in sulpiridetreated mares than in control mares maintained under identical environmental conditions. Similar fertility at first ovulation was observed in sulpiride-treated and control mares, demonstrating that ovulations occurring during sulpiride-treatment are fertile ovulations. These findings are in agreement with our previous observation that the luteal phase after the first ovulation in sulpiride-treated mares is of normal length and that progesterone secretion during the first luteal phase is similar to that in untreated mares (Besognet et al., 1995a). These results lend continued support to our premise that the administration of a dopamine D2 antagonist may be a useful tool to advance the time of first ovulation in seasonally anoestrous mares and may offer a practical alternative to exposure to artificial photoperiod.

The study reported here confirms the existence of a pulsatile pattern of secretion of gonadotrophins during the nonbreeding season in mares, with gonadotrophin pulse frequencies similar to those reported in previous studies (Alexander and Irvine, 1986, 1991; Thompson et al., 1987; Fitzgerald et al., 1987; Hines et al., 1991). Our results suggest that sulpiride treatment alters the mode of FSH secretion during the transitional period by increasing FSH pulse frequency and mean plasma concentration. A significantly higher FSH pulse frequency was observed only on the first day of treatment in sulpiride-treated mares and significantly higher mean plasma concentrations were observed only on day 11 of treatment. The lack of significant difference on other days may be due in part to a seasonal increase in FSH pulse frequency and plasma concentrations in nontreated mares combined with the relatively small number of animals per group. A rise in FSH and $\mathrm{LH}$ pulse frequency and in mean FSH concentration has previously been reported during the transitional period in mares, with a decrease in pulse amplitude (Fitzgerald et al., 1987; Thompson et al., 1987; Alexander and Irvine, 1991; Hines et al., 1991). Observations in cyclic and transitional mares suggest that FSH plays a major role in follicular development and seasonal recrudescence of ovarian development (Ginther, 1992; Alexander and Irvine, 1993). In cyclic mares, it has been shown that emergence of follicular waves (including the primary follicular wave giving rise to the dominant ovulatory follicle) is associated with high FSH concentrations. An increase in mean concentrations of FSH was shown to begin a few days before 

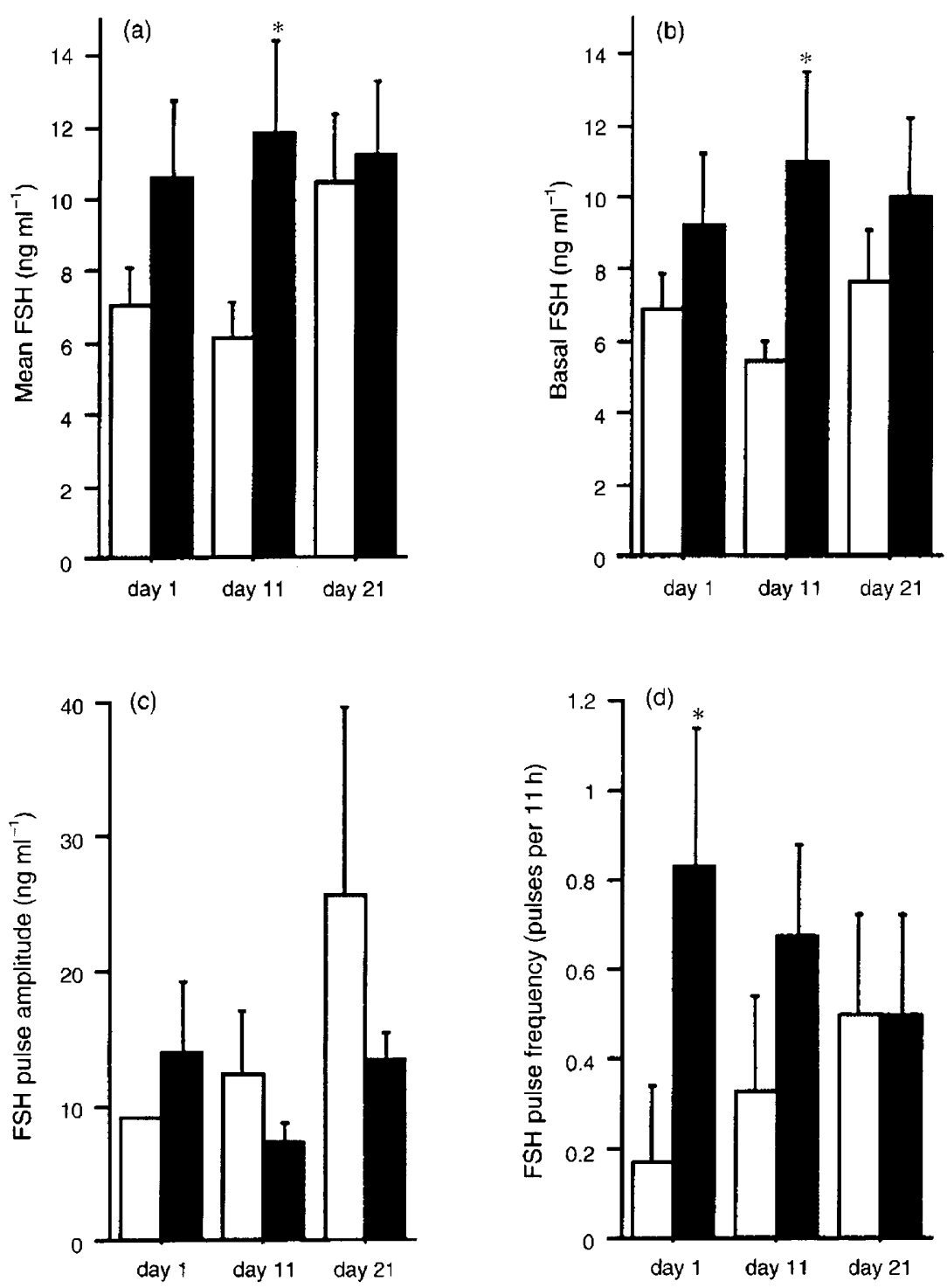

Fig. 2. (a) Mean and (b) basal plasma FSH concentrations, FSH pulse (c) amplitude and (d) frequency in mares treated with sulpiride $(\boldsymbol{\square}, n=6)$ or nontreated mares $(\square, n=6)$ (means \pm SEM). Blood samples were taken every $15 \mathrm{~min}$ for $11 \mathrm{~h}$ on days 1,11 and 21 of treatment. ${ }^{*}$ Indicates significantly different from control $(P \leq 0.05)$.

the dominant follicle of a primary follicular wave reached $15 \mathrm{~mm}$, and the number of $2-3 \mathrm{~mm}$ diameter follicles increased in temporal association with increased exposure to $\mathrm{FSH}$ (Ginther and Bergfelt, 1992, 1993). In our study, FSH pulses were observed more frequently in mares that ovulated early, both in sulpiride-treated and non-treated mares. In mares that ovulated later in spring (after day 100), very few pulses were observed. This is in agreement with the observation that, during the vernal transition, the increase in ovarian activity is associated with a gradual increase in FSH pulse frequency (Alexander and Irvine, 1991; Hines et al., 1991). Therefore, it seems reasonable to conclude that the change in ovarian activity, with advanced follicular development leading to an early ovulation in sulpiride-treated mares, was due to changes in FSH secretion, that is, an increase in FSH pulse frequency and mean plasma concentration.
In contrast, no effect of treatment on the pattern of $\mathrm{LH}$ pulsatile secretion could be demonstrated in the study reported here. It remains possible that low amplitude LH pulses escaped detection in our experiment. Other studies with cyclic mares strongly support the hypothesis that GnRH is the major signal for both LH and FSH secretion, and changes in pituitary responsiveness may modulate their relative secretion (Irvine and Alexander, 1993, 1994). With advancing stage of the transitional period, the FSH response decreases in contrast to the LH response, which increases (Silvia et al., 1986). We propose that sulpiride treatment may exert an effect on GnRH secretion during anoestrus, via a decrease in dopaminergic inhibition of $\mathrm{GnRH}$ neurones, resulting in increased frequency of FSH pulses.

In anoestrous ewes, there is strong evidence that dopaminergic inhibition of $\mathrm{GnRH}$ neurones is the mechanism of 

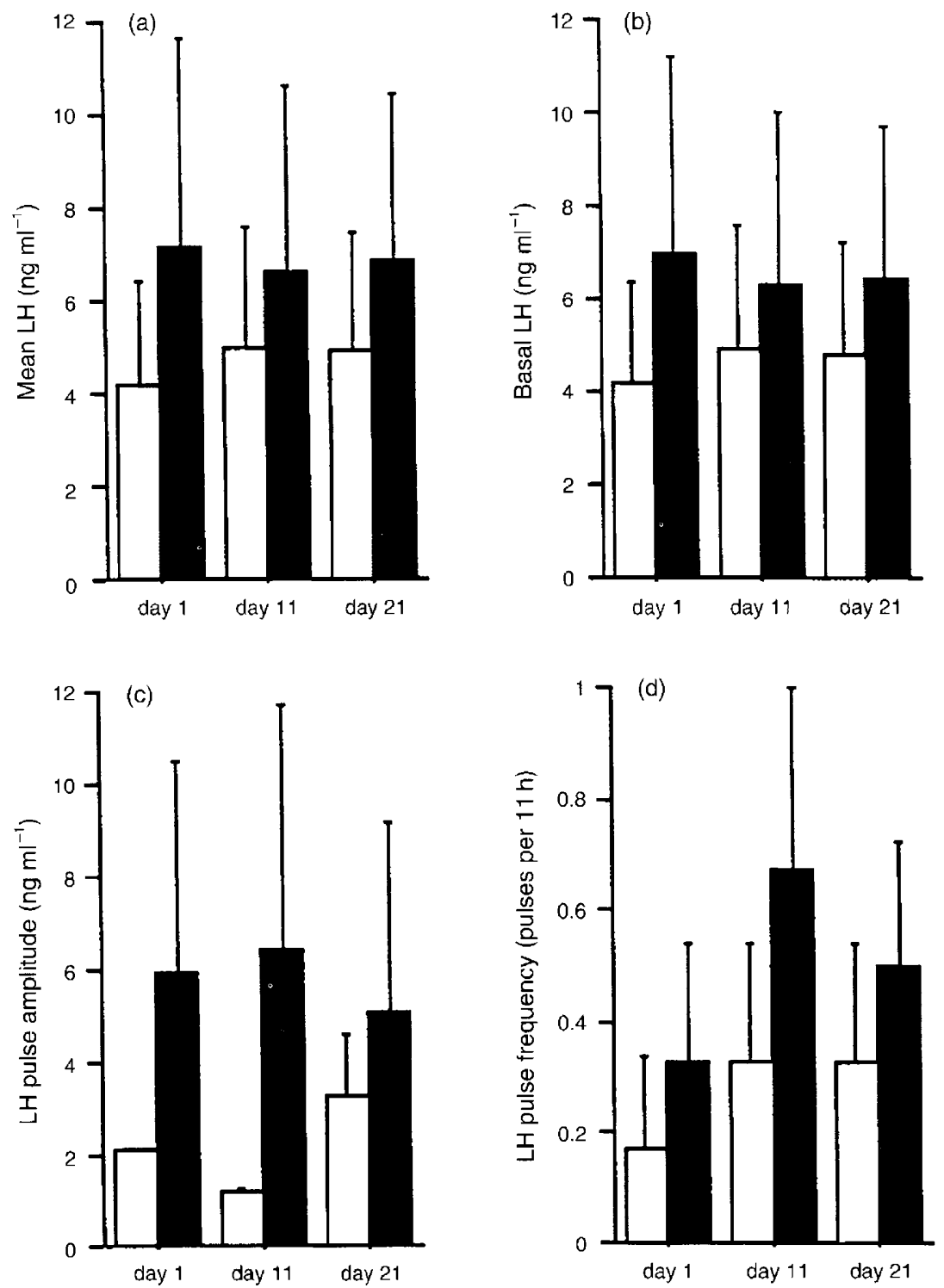

Fig. 3. (a) Mean and (b) basal plasma LH concentrations, LH pulse (c) amplitude and (d) frequency in mares treated with sulpiride $(\boldsymbol{\square}, n=6)$ or nontreated mares $(\square, n=6)$ (means \pm SEM). Blood samples were taken every $15 \mathrm{~min}$ for $1 \mathrm{I} \mathrm{h}$ on days 1,11 and 21 of treatment. No significant difference was observed between treated and nontreated groups $(P>0.05)$.

the negative feedback of oestradiol on $\mathrm{LH}$ secretion during anoestrus (Havern et al., 1994). A negative feedback of oestrogens on gonadotrophin secretion during anoestrus has also been suggested in mares because oestradiol administration decreases LH and FSH secretion (Squires, 1993). In contrast, at the end of the vernal transition, oestrogens exert a positive feedback on LH secretion and may play a stimulatory role in the ovulatory surge of LH (Sharp et al., 1991). In mares, the existence of a switch from a negative feedback to a positive feedback of oestradiol on gonadotrophin secretion, as is the case in sheep for LH secretion during the transition from anoestrus to oestrus, has never been demonstrated but may exist. In addition to an ovarian-dependent mechanism suppressing gonadotrophin secretion, a gonadal-independent mechanism may also exist in mares (Sharp, 1988; Affleck et al., 1991). A direct effect on the ovaries can not be excluded based on the present experiment. While there are no reports on direct effect of dopamine antagonist on ovarian function, an effect of sulpiride-induced prolactin secretion on ovarian function needs to be considered in the present study. In several mammalian species, prolactin receptors have been demonstrated in the ovaries and prolactin has been implicated in various inhibitory and stimulatory functions (Kawagoe and Hiroi, 1989; Clarke et al., 1993; Kermabon ef al., 1994). However, our previous observations do not support a role for prolactin in the seasonal transition from anoestrus to reproductive function in mares (Besognet et al., 1995b).

Sulpiride treatment advances significantly the onset of continued cyclic ovulatory activity in anoestrous mares, as is 
the case with artificial photoperiod treatment. In contrast, exogenous GnRH treatment in January or February induces one ovulatory cycle, but is usually followed by a return to anoestrus (McCue et al., 1991; Mumford et al., 1994).

The depth of the anoestrus in individual mares is difficult to measure and is very variable (Ginther, 1992). It is conceivable that inhibitory and stimulatory mechanisms, regulated by factors such as photoperiod, temperature and nutrition, may be active during seasonal anoestrus and the transition period into the breeding season. The relative importance of each mechanism may contribute to the large variation in the time of onset of reproductive activity in individual mares and thus could explain some of the variability in the response to sulpiride treatment.

In conclusion, the results of the study reported here indicate that dopamine is part of the inhibitory mechanism of reproductive activity during seasonal anoestrus in mares, probably acting via the modulation of FSH pulsatile secretion.

The authors thank A. C. O. Evans for valuable help and advice, A. J. McClure for excellent technical assistance and the staff at the Equine Research Park at Comell University for animal care. The provision of reagents by J. F. Roser, H. Papkoff (University of California, Davis, CA) and the National Hormone and Pituitary Program (Rockville, MD) is gratefully acknowledged.

\section{References}

Affleck KJ, Conboy HS and Fitzgerald BP (1991) A negative feedback role for the ovaries of the mare on tonic LH secretion before the first ovulation of the breeding season Journal of Reproduction and Fertility Supplement 44 241-247

Alexander SL and Irvine CHG (1986) Effect of graded doses of gonadotrophinreleasing hormone on serum $\mathrm{LH}$ concentrations in mares in various reproductive states: comparison with endogenously generated LH pulses Journal of Endocrinology 110 19-26

Alexander SL and Irvine CHG (1991) Control of onset of breeding season in the mare and its artificial regulation by progesterone treatment Journal of Reproduction and Fertility Supplement 44 307-318

Alexander SL and Irvine CHG (1993) FSH and LH. In Equine Reproduction, PP 45-56 Eds AO McKinnon and JL Voss. Lea \& Febiger, Philadelphia

Besognet B, Hansen BS and Daels PF (1995a) The role of dopamine in the regulation of seasonal reproductive activity in mares Biology of Reproduction 52 (Supplement 1) 203

Besognet B, Hansen BS and Daels PF (1995b) Prolactin secretion during the transitional phase and the relationship to onset of reproductive season in mares Biology of Reproduction Monograph Series1 459-467

Clarke DL, Arey BJ and Linzer DIH (1993) Prolactin receptor messenger ribonucleic acid expression in the ovary during the rat estrous cycle Endocrinology 133 2594-2603

Fitzgerald BP, Affleck KJ, Barrows SP, Murdoch WL, Barker KB and Loy RG (1987) Changes in LH pulse frequency and amplitude in intact mares during the transition into the breeding season Journal of Reproduction and Fertility 79 $485-493$

Ginther OI (1992) Reproductive Biology of the Mare. Basic and Applied Aspects. 2nd edn. Equiservices, Cross Plains

Ginther OJ and Bergfelt DR (1992) Ultrasonic characterization of follicular waves in mares without maintaining identity of individual follicle Journal of Equine Veterinary Science 12 349-354

Ginther OJ and Bergfelt DR (1993) Growth of small follicles and concentrations of FSH during the equine oestrous cycle Journal of Reproduction and Fertility 99 105-111

Havern RL, Whisnant CS and Goodman RL (1994) Dopaminergic structures in the ovine hypothalamus mediating estradiol negative feedback in anestrous ewes Endocrinology 134 1905-1914

Hines KK, Affleck KJ, Barrows WL, Murdoch WL, Fitzgerald BP and loy RG (1991) Follicle-stimulating hormone pulse amplitude decreases with the onset of the breeding season in the mares Biology of Reproduction 44 $516-521$
Irvine CHG and Alexander SL (1993) Secretory patterns and rates of gonadotropin-releasing hormone, follicle-stimulating hormone, and luteinizing hormone revealed by intensive sampling of pituitary venous blood in the luteal phase mare Endocrinology 132 212-218

Irvine CHG and Alexander SL (1994) The dynamics of gonadotropin-releasing hormone, LH and FSH secretion during the spontaneous ovulatory surge of the mare as revealed by intensive sampling of pituitary venous blood Journal of Endocrinology 140 283-295

Kao C, Schaeffer DJ and Jackson GL (1992) Different neuroendocrine systems modulate pulsatile luteinizing hormone secretion in photosuppressed and photorefractory ewes Biology of Reproduction 46 425-434

Kawagoe S and Hiroi M (1989) Further evidence that prolactin controls the prepubertal sexual development in the female rat Gynecologic and Obstetric Investigation 27 197-200

Kermabon AY, Belair L, Theau-Clement M, Salesse R and Djiane J (1994) Effects of anoestrus and bromocryptine treatment on the expression of prolactin and LH receptors in the rabbit ovary during lactation Journal of Reproduction and Fertility 102 131-1.38

Le Corre S and Chemineau P (1993) Control of photoperiodic inhibition of luteinizing hormone secretion by dopaminergic and serotoninergic systems in ovariectomized Ile-de-France ewes supplemented with oestradiol Journal of Reproduction and Fertility 97 367-373

McCue PM, Troedsson MHT, Liu IKM, Stabenfeldt GH, Hughes JP and Lasley BL. (1991) Follicular and endocrine responses of anoestrous mares to administration of native $\mathrm{GnRH}$ or a $\mathrm{GnRH}$ agonist Journal of Reproduction and Fertility Supplement 44 227-233

Merriam GR and Wachter KW (1982) Algorithms for the study of episodic hormone secretion American Journal of Physiology 243 E310-E318

Meyer SL and Goodman RL (1985) Neurotransmitters involved in mediating the steroid-dependent suppression of pulsatile luteinizing hormone secretion in anestrous ewes: effect of receptor antagonists Endocrinology 116 2054-2061

Meyer SL and Goodman RL (1986) Separate neural systems mediate the steroid-dependent and steroid-independent suppression of tonic luteinizing hormone secretion in the anestrous ewe Biology of Reproduction 35 562-571

Mumford EL, Squires EL, Peterson KD, Nett TM and Jasko DJ (1994) Effect of various doses of a gonadotropin-releasing hormone analogue on induction of ovulation in anestrous mares Journal of Animal Science 72 178-183

Munro C and Stabenfeld G (1984) Development of microtitre plate enzyme immunoassay for the determination of progesterone Journal of Endocrinology $10141-49$

Roser JF and Hughes JP (1991) Prolonged pulsatile administration of gonadotrophin releasing hormone ( $\mathrm{GnRH})$ to fertile stallions Journal of Reproduction and Fertility Supplement 44 155-168

Seki K, Kato K and Shima K (1986) Parallelism in the luteinizing hormone responses to opioid and dopamine antagonists in hyperprolactinemic women with pituitary microadenoma Journal of Clinical Endocrinology and Metabolism 63 1225-1228

Sharp DC (1988) Transition into the breeding season: clues to the mechanisms of seasonality Equine Veterinary Journal 20 159-161

Sharp DC, Grubaugh WR, Weithenauer J, Davis SD and Wilcox CJ (1991) Effects of steroid administration on pituitary luteinizing hormone and folliclestimulating hormone in ovariectomized pony mares in the early spring: pituitary responsiveness to gonadotropin-releasing hormone and pituitary gonadotropin content Biology of Reproduction 44 983-990

Silvia PJ, Squires EL and Nett TM (1986) Changes in the hypothalamichypophyseal axis of mares associated with seasonal reproductive recrudescence Biology of Reproduction 35 897-905

Sotowska-Brochocka J, Martynska L and Licht P (1994) Dopaminergic inhibition of gonadotropic release in hibernating frogs, Rana temporaria General and Comparative Endocrinology 93 192-196

Squires EL (1993) Puberty. In Equine Reproduction, pp 114-120 Eds AO McKinnon and JL Voss. Lea \& Febiger, Philadelphia

Thompson DL, McNeill DR, Wiest JJ, St George RL, Jones LS and Garza F, Jr (1987) Secretion of luteinizing hormone in intact and ovariectomized mares in summer and winter Journal of Animal Sciences 64 247-253

Thompson FN, Jones RD, Stuedemann JA, Mizinga KM and Smith BS (1992) Effect of metoclopramide on luteinizing hormone secretion in postpartum cows American Journal of Veterinary Research 53 727-730

Van Asselt LAC, Goos HJT, Smit-Van Dijk W, Speetjens PAM and Van Oordt PGWJ (1988) Evidence for the involvement of D2 receptors in the dopaminergic inhibition of gonadotropin release in the African catfish. Clarias gariepinus Aquaculture 72 369-378 